\title{
Comparison of Gross Motor Skills of 8-10 Years Old Students Active in Different Sport Branches
}

\author{
Ebru Aydin ${ }^{1}$ \\ Meryem Gulac ${ }^{\circledR}$
}

'PhD Student, Institute of Social Sciences, Department of Physical Education and Sports, Dumlupinar

University, Turkey.

Email: marmorierung@gmail.com Tel:+905052085493

'Kütahya Dumlupinar University, School of Physical Education and Sports, Kütahya, Turkey.

Email:meryem.gulac@dpu.edu.tr Tel:+905079436113

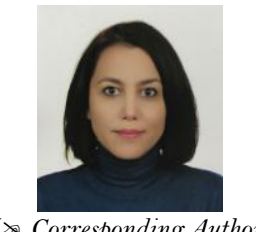

( Corresponding Author)

\begin{abstract}
The aim of this study was to investigate the basic motor skill levels of 8-10 years old children active in different sports branches according to TGMD-III test depending on the levels of gender and sports branches. The study encompassed 239 athletes of 8-10 age groups on a voluntary basis who had been doing sports for at least one year. The data required to achieve the objectives determined in the research were obtained using TGMD-III test protocol. Kurtosis-Skewness and Kolmagorov-Smirnov analyses were performed for normality test of data and it was found that the data were not distributed normally and so nonparametric tests were used. Mann Whitney U test was used for paired groups and Kruskal Wallis analysis was used for comparison of the others. In TGMD-III gender comparison of the athletes, a significant difference was found in total Locomotor tests, total object control and total TGMD-III $(\mathrm{p}<0.01)$. There are significant differences in the comparison of TGMD-III sports branch of the athletes in Locomotor tests total, object control tests total and TGMD-III overall total $(\mathrm{p}<0.01)$. As a result, the gross motor skills of the footballers were found to be significantly better compared to the other branches. It is thought that the difference between the branches resulted from the motoric and physiological characteristics required by the structures of the branches. In addition, sports age and training styles of the athletes are thought to have affected the measurement results.
\end{abstract}

Keywords: Psychomotor development, TGMD-III, Locomotor skills, Object control, Sports branches, Football.

Citation | Ebru Aydin; Meryem Gulac (2019). Comparison of Gross Motor Skills of 8-10 Years Old Students Active in Different Sport Branches. Asian Journal of Education and Training, 5(4): 582-588. History:

Received: 10 September 2019

Revised: 11 October 2019

Accepted: 18 November 2019

Published: 16 December 2019

Licensed: This work is licensed under a Creative Commons Attribution 3.0 License (cc) E

Publisher: Asian Online Journal Publishing Group
Acknowledgement: Both authors contributed to the conception and design of the study.

Funding: This study received no specific financial support.

Competing Interests: The authors declare that they have no conflict of interests.

Transparency: The authors confirm that the manuscript is an honest, accurate, and transparent account of the study was reported; that no vital features of the study have been omitted; and that any discrepancies from the study as planned have been explained.

Ethical: This study follows all ethical practices during writing.

\section{Contents}

1. Introduction

2. Method 


\section{Contribution of this paper to the literature}

This study will contribute to the literature about gross motor development of 8-10 years old children, who do sports in basketball, football, volleyball, gymnastics and taekwondo branches, according to TGMD-III test.

\section{Introduction}

Today, sport is considered as a part of a healthy and balanced life and one of the most beneficial social activities (Kürkçü and Gökhan, 2011). For all sports branches, as well as the ability and skill, the importance of physiological and physical fitness is increasing day by day (Bilgiç et al., 2016). Every healthy person has the ability to move. However, the extent to which this ability can be improved is different. In addition to the structural quality that determines the extent of development, supporting this feature with education from a very early age, the quality of the training and the characteristic of the sports branch form the basis of the increasing success of sports (Dündar, 1995). Timmons et al. (2007) state that physical activity and sports provide motor development in children and form the basis of health. Today, interest in sports is increasing day by day. Along with the interest in sports, important studies are being made on motor development. We know that none of our skills and talents will ever evolve without any work. Especially if we want to make changes and improvements in motor skills in children at developmental ages, it is absolutely necessary to prepare suitable training programs for them and to train them with a conscious coach. Of course, the level of development and individual differences between children should be taken into consideration while conducting these programs (Koç, 2005). In this respect, in our study, it was aimed to examine the gross motor skills of the athletes in different sports branches.

\section{Method}

\subsection{Population}

The population of the study was comprised of 8-10 age group students who were actively involved in basketball, football, volleyball, gymnastics and taekwondo in Izmir Metropolitan Municipality Ord. Professor Dr. Ekrem Akurgal Multi-Purpose Gymnasium.

\subsection{Research Group}

The research group was comprised of 8-10 age group male and female athletes in basketball (51), football (48), volleyball (52), gymnastics (37) and taekwondo (51) in Ord. Professor Dr. Ekrem Akurgal Multi-Purpose Gymnasium. The measurements were taken on a total of 239 athletes participating voluntarily.

\subsection{Research Technique and Protocol}

239 athletes, who had been doing sports in Izmir Metropolitan Municipality Youth and Sports Club Ord. Professor Dr. Ekrem Akurgal Gymnasium for at least one year, participated in the study on a voluntary basis. Firstly, permission was sought from the official of Izmir Metropolitan Municipality Youth and Sports Club Ord. Professor Dr. Ekrem Akurgal Multi-purpose Gymnasium to perform the tests. In addition, parents' consent form was taken from each student's parent before taking the measurement for the tests. After obtaining these permissions, the implementation started. The data required to achieve the objectives determined in the study were obtained by applying (Webster and Ulrich, 2017) TGMD-III test protocol. Motor tests in the TGMD-III test were applied in the gym where students were doing sports. The necessary equipment for the test was prepared before the students came to the gym where the test will be performed. After the students gathered in the gym, the names were read from the list prepared before and attendance was checked. After the attendance check, short information was given about the skills to be examined. After the explanation, the subjects were taken one by one and the test was shown and explained in a simple way and the student was asked to practice. The skills were first started with object control skills and continued with locomotor skills. If the drill was done perfectly according to the criteria in the test, 1 was not entered and if not, $O$ was entered to the data form immediately. There is no half credit allocated for this evaluation.

\subsection{Data Collection Tool}

TGMD-III was started to develop by Dale Ulrich in 2013 and completed in 2015. Kip Webster also helped develop TGMD-III test. It was designed to test the motor behaviours of children aged 3 to 10 years. TGMD-III assesses 13 basic motor skills divided into two sub-groups. These are Locomotor and Object Control skills. Locomotor subtest measures running, skipping, horizontal jumping, hopping, galloping and sliding skills. The object control subtest measures two hand strike, one hand forehand, dribbling, two hand catch, kickingmasa te, overhand throw and underhand throw. The TGMD-III test is a direct observation and process-oriented skill assessment, reflecting the most mature form of movement, looking at 3-5 performance criteria per skill. In accordance with performance criteria, 1 point is given for smooth and correct movements and o point is given for wrong and uneven movements. At the end of the test, the total score of each action performed twice is added to form the score of that skill. A total of 46 points can be obtained in the locomotor subtest and 54 points can be obtained in the object control subtest, giving 100 full points in total. The average duration of each test to a child is 15-20 minutes. The child must repeat each movement twice. The validity and reliability studies of the TGMD-III test were performed and the reliability of the test was determined as 0.97 for locomotor tests and 0.95 for object control tests. Total TGMD-III was reported as 0.97. Also, it was determined that TGMD-III showed acceptable construct validity (Webster and Ulrich, 2017).

\subsection{Data Analysis}

Kurtosis-Skewness and Kolmagorov-Smirnov analyses were performed for the normality test of the data and it was found that the data were not distributed normally. For the data sets that did not show normal distribution, kurtosis and skewness values were examined and nonparametric test was used since the values were not between 
+2/-2 (George and Mallery, 2010). Mann Whitney U was used for gender and Kruskal Wallis test was used for comparison of the branches in comparison of the data. As a second level test, Tamhane's T2 post hoc test was used to compare the branches. Significance level was taken as 0.05.

\section{Findings}

Table-1. Normality test.

\begin{tabular}{l|l|c|c|r}
\hline \multirow{2}{*}{ Total } & \multirow{2}{*}{ Sport branch } & \multicolumn{3}{c}{ Kolmogorov-Smirnov } \\
\cline { 2 - 5 } & & Statistics & Df & \multicolumn{1}{c}{ P } \\
\hline \multirow{4}{*}{ Locomotor total } & Basketball & .336 & 51 & $.000^{*}$ \\
\cline { 2 - 5 } & Volleyball & .192 & 52 & $.000^{*}$ \\
\cline { 2 - 5 } & Gymnastics & .169 & 37 & $.009^{*}$ \\
\cline { 2 - 5 } & Taekwondo & .380 & 51 & $.000^{*}$ \\
\cline { 2 - 5 } & Football & .532 & 48 & $.000^{*}$ \\
\hline \multirow{4}{*}{ Manipulative total } & Basketball & .231 & 51 & $.000^{*}$ \\
\cline { 2 - 5 } & Volleyball & .146 & 52 & $.007^{* *}$ \\
\cline { 2 - 5 } & Gymnastics & .152 & 37 & $.031^{* *}$ \\
\cline { 2 - 5 } & Taekwondo & .140 & 51 & $.013^{* *}$ \\
\cline { 2 - 5 } & Football & .239 & 48 & $.000^{*}$ \\
\hline \multirow{4}{*}{ TGMD-III total } & Basketball & .270 & 51 & $.000^{*}$ \\
\cline { 2 - 5 } & Volleyball & .144 & 52 & $.009^{* *}$ \\
\cline { 2 - 5 } & Gymnastics & .180 & 37 & $.004^{*}$ \\
\cline { 2 - 5 } & Taekwondo & .176 & 51 & $.000^{*}$ \\
\cline { 2 - 5 } & Football & .208 & 48 & $.000^{*}$ \\
\hline
\end{tabular}

$\overline{\mathrm{P}=\text { Difference. }^{*}=(\mathrm{p}<0.01){ }^{*} * *=(\mathrm{p}>0.05)}$.

Since the total and number of branches were above $\mathrm{N}=30$ in the normality test, according to the KolmogrovSmirnov test Table 1, it is seen that the data did not show normal distribution at $\mathrm{p}<0.05$ significance level. Based on these data, skewness and kurtosis tests were found conducted.

Table-2. Skewness and Kurtosis values.

\begin{tabular}{|c|c|c|c|c|c|c|c|c|c|}
\hline \multirow{2}{*}{ Total } & $\mathbf{N}$ & Min. & Max. & Mean. & Std. Dev. & \multicolumn{2}{|c|}{ Skewness } & \multicolumn{2}{|c|}{ Kurtosis } \\
\hline & \multicolumn{5}{|c|}{ Statistics } & Statistics & Std. Err. & Statistics & Std. Err. \\
\hline Locomotor total & 239 & 13.00 & 23.00 & 21.61 & 1.93 & -1.745 & .157 & 3.376 & .314 \\
\hline Manipulative total & 239 & 15.00 & 27.00 & 24.39 & 2.44 & -1.319 & .157 & 2.522 & .314 \\
\hline TGMD-III total & 239 & 28.00 & 50.00 & 46.00 & 4.02 & -1.839 & .157 & 4.467 & .314 \\
\hline
\end{tabular}

$\mathrm{N}=$ Number of Participants. Min.= Minimum Value. Max. = Maximum Value. Mean.= Average. Std. Dev.=Standard Deviation. Std.Err.= Standard Error.

Kurtosis-Skewness values Table 2 were examined for data sets that do not show normal distribution and since the values were not between $+2 /-2$, it was determined that the data did not show normal distribution (George and Mallery, 2010).

\begin{tabular}{|c|c|c|c|c|c|c|c|}
\hline TGDM3 & Gender & $\mathbf{N}$ & Minimum & Maximum & Mean & Standard deviation & $\mathbf{P}$ \\
\hline \multirow{3}{*}{ Locomotor tests } & Female & 105 & 13.00 & 23.00 & 20.95 & 2.12 & \multirow{3}{*}{$.000^{*}$} \\
\hline & Male & 134 & 15.00 & 23.00 & 22.12 & 1.59 & \\
\hline & Total & 239 & 13.00 & 23.00 & 21.61 & 1.93 & \\
\hline \multirow{3}{*}{ Object control tests } & Female & 105 & 15.00 & 27.00 & 23.70 & 2.65 & \multirow{3}{*}{$.000^{*}$} \\
\hline & Male & 134 & 15.00 & 27.00 & 24.93 & 2.11 & \\
\hline & Total & 239 & 15.00 & 27.00 & 24.39 & 2.44 & \\
\hline \multirow{3}{*}{ TGMD-III overall total } & Female & 105 & 28.00 & 50.00 & 44.65 & 4.42 & \multirow{3}{*}{$.000^{*}$} \\
\hline & Male & 134 & 30.00 & 50.00 & 47.05 & 3.32 & \\
\hline & Total & 239 & 28.00 & 50.00 & 46.00 & 4.02 & \\
\hline
\end{tabular}

In the TGMD-III gender comparison of the athletes Table 3, the mean of female participants was (20.95 \pm 2.12$)$ and the mean of male participants was $(22.12 \pm 1.59)$ in locomotor tests. The mean of female participants was $(23.70 \pm 2.65)$ and the mean of male participants was $(24.93 \pm 2.11)$ in total object control tests. (24.93 \pm 2.11$)$. The mean of female participants was $(44.65 \pm 4.42)$, while the mean of male participants $(47.05 \pm 3.32)$ in the TGMD-III overall total. There were statistically significant differences in total locomotor tests, object control total and TGMD-III total $(\mathrm{p}<0.01)$. 
Table-4. TGMD-III Sports branch comparison of the participants.

\begin{tabular}{|c|c|c|c|c|c|c|c|}
\hline TGMD-III & Sport branch & $\mathbf{N}$ & Minimum & Maximum & Mean & Standard deviation & $\mathbf{P}$ \\
\hline \multirow{6}{*}{ Locomotor tests } & Basketball & 51 & 15.00 & 23.00 & 21.72 & 2.11 & \multirow{6}{*}{$.000^{*}$} \\
\hline & Volleyball & 52 & 13.00 & 23.00 & 20.03 & 2.30 & \\
\hline & Gymnastics & 37 & 18.00 & 23.00 & 21.37 & 1.29 & \\
\hline & Taekwondo & 51 & 18.00 & 23.00 & 22.13 & 1.38 & \\
\hline & Football & 48 & 20.00 & 23.00 & 22.81 & 0.64 & \\
\hline & Total & 239 & 13.00 & 23.00 & 21.61 & 1.93 & \\
\hline \multirow{6}{*}{ Object control tests } & Basketball & 51 & 15.00 & 27.00 & 24.98 & 2.74 & \multirow{6}{*}{$.000^{*}$} \\
\hline & Volleyball & 52 & 15.00 & 27.00 & 23.05 & 2.96 & \\
\hline & Gymnastics & 37 & 20.00 & 27.00 & 23.08 & 1.83 & \\
\hline & Taekwondo & 51 & 22.00 & 27.00 & 24.74 & 1.54 & \\
\hline & Football & 48 & 22.00 & 27.00 & 25.85 & 1.23 & \\
\hline & Total & 239 & 15.00 & 27.00 & 24.39 & 2.44 & \\
\hline \multirow{6}{*}{ TGMD-III overall total } & Basketball & 51 & 30.00 & 50.00 & 46.70 & 4.64 & \multirow{6}{*}{$.000^{*}$} \\
\hline & Volleyball & 52 & 28.00 & 50.00 & 43.09 & 5.02 & \\
\hline & Gymnastics & 37 & 39.00 & 50.00 & 44.45 & 2.51 & \\
\hline & Taekwondo & 51 & 41.00 & 50.00 & 46.88 & 2.06 & \\
\hline & Football & 48 & 45.00 & 50.00 & 48.66 & 1.50 & \\
\hline & Total & 239 & 28.00 & 50.00 & 46.00 & 4.02 & \\
\hline
\end{tabular}

In the TGMD-III sports branch of the athletes Table 4, the average of the basketball players in the locomotor

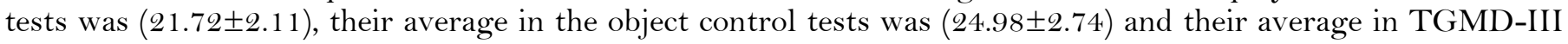
overall total was $(46.70 \pm 4.64)$. The average of the volleyball players in total locomotor tests was (20.03 \pm 2.30$)$, their average in object control tests total was $(23.05 \pm 2.96)$ and their average in TGMD-III overall total was

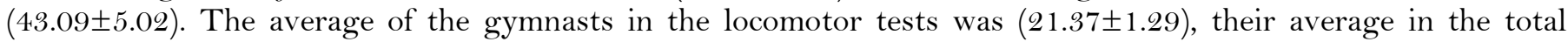
object control tests was $(23.08 \pm 1.83)$ and their average in TGMD-III overall total was $(46.45 \pm 2.51)$. The average

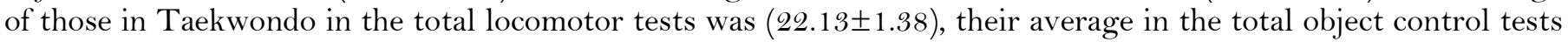
was $(24.74 \pm 1.54)$ and their average in TGMD-III overall total was $(46.88 \pm 2.06)$. The average of the footballers in the total locomotor tests was $(22.81 \pm 0.64)$, their average in the total object control tests was $(25.85 \pm 1.23)$ and their average in TGMD-III overall total was $(48.66 \pm 1.50)$. There are statistically significant differences in total locomotor tests, total object control tests and TGMD-III overall total $(\mathrm{p}<0.01)$.

Table-5. Comparison of the sport branches according to TGMD-III overall total.

\begin{tabular}{|c|c|c|c|c|c|c|}
\hline \multirow{2}{*}{ (1) Sport branch } & \multirow{2}{*}{ (2) Sport branch } & \multirow{2}{*}{ Mean difference (1-2) } & \multirow{2}{*}{ Std. Err. } & \multirow{2}{*}{$\mathbf{P}$} & \multicolumn{2}{|c|}{$\% 95$ Confidence range } \\
\hline & & & & & Limit inferior & Limit superior \\
\hline \multirow{4}{*}{ Basketball } & Volleyball & $3.60973^{*}$ & .95374 & $.003^{*}$ & .8798 & 6.3397 \\
\hline & Gymnastics & $2.24642^{*}$ & .77092 & $.045^{* *}$ & .0272 & 4.4657 \\
\hline & Taekwondo & -.17647 & .71232 & 1.000 & -2.2365 & 1.8836 \\
\hline & Football & -1.96078 & .68632 & .057 & -3.9543 & .0327 \\
\hline \multirow{4}{*}{ Volleyball } & Basketball & $-3.60973^{*}$ & .95374 & $.003^{*}$ & -6.3397 & -.8798 \\
\hline & Gymnastics & -1.36331 & .81020 & .637 & -3.6965 & .9699 \\
\hline & Taekwondo & $-3.78620^{*}$ & .75466 & $.000^{*}$ & -5.9697 & -1.6027 \\
\hline & Football & $-5.57051^{*}$ & .73017 & $.000^{*}$ & -7.6916 & -3.4494 \\
\hline \multirow{4}{*}{ Gymnastics } & Basketball & $-2.24642^{*}$ & .77092 & $.045^{* *}$ & -4.4657 & -.0272 \\
\hline & Volleyball & 1.36331 & .81020 & .637 & -.9699 & 3.6965 \\
\hline & Taekwondo & $-2.42289^{*}$ & .50419 & $.000^{*}$ & -3.8816 & -.9642 \\
\hline & Football & $-4.20721^{*}$ & .46674 & $.000^{*}$ & -5.5679 & -2.8465 \\
\hline \multirow{4}{*}{ Taekwondo } & Basketball & .17647 & .71232 & 1.000 & -1.8836 & 2.2365 \\
\hline & Volleyball & 3.78620* & .75466 & $.000^{*}$ & 1.6027 & 5.9697 \\
\hline & Gymnastics & $2.42289^{*}$ & .50419 & $.000^{*}$ & .9642 & 3.8816 \\
\hline & Football & $-1.78431^{*}$ & .36184 & $.000^{*}$ & -2.8224 & -.7463 \\
\hline \multirow{4}{*}{ Football } & Basketball & 1.96078 & .68632 & .057 & -.0327 & 3.9543 \\
\hline & Volleyball & $5.57051^{*}$ & .73017 & $.000^{*}$ & 3.4494 & 7.6916 \\
\hline & Gymnastics & $4.20721^{*}$ & .46674 & $.000^{*}$ & 2.8465 & 5.5679 \\
\hline & Taekwondo & $1.78431^{*}$ & .36184 & $.000^{*}$ & .7463 & 2.8224 \\
\hline
\end{tabular}

There was a statistically significant difference between basketball branch and volleyball in comparison of sports branches based on TGMD-III overall total $(\mathrm{p}<0.01)$ Table 5 . There was a statistically significant difference between basketball and gymnastics $(\mathrm{p}<0.05)$. There was no statistically significant difference between basketball and other branches $(\mathrm{p}>0.05)$. There was a statistically significant difference between volleyball branch and basketball, taekwondo and football $(\mathrm{p}<0.01)$. There was no statistically significant difference between volleyball 
and gymnastics $(\mathrm{p}>0.05)$. There was a statistically significant difference between gymnastics and taekwondo and football $(\mathrm{p}<0.01)$. There was a statistically significant difference between Taekwondo branch and volleyball, gymnastics and football $(\mathrm{p}<0.01)$. There was no statistically significant difference between taekwondo and basketball $(\mathrm{p}>0.05)$. There was a statistically significant difference between football branch and volleyball, gymnastics and taekwondo $(\mathrm{p}<0.01)$. There was no statistically significant difference between football and basketball $(\mathrm{p}>0.05)$.

\section{Discussion}

There was a significant difference in the TGMD-III gender comparison of the athletes in total locomotor tests, total object control and total TGMD-III $(\mathrm{p}<0.00)$.

In TGMD-III Locomotor Skills, Aydin (2009) investigated the motor development levels of the 10-age group students, who participated indoor sports events in the city of Kütahya, according to TGMD-II test. This study was conducted with similar measurement methods and a statistically significant difference was found according to gender in locomotor skill levels which is one of the sub-dimensions of TGMD-II Test $(\mathrm{P}<0.05)$. Spessato et al. (2013) showed in their study with 3-10 aged children that there was a significant difference in locomotor total scores of boys in locomotor skills compared to girls in 7-8 and 9-10 age group and boys were found to be better than girls. This study is similar to our study. Again in 2011, Ylldirım investigated the psychomotor development levels of 7-8 age group girls and boys according to TGMD-II test depending on gender variable, and the difference between TGMD-II test locomotor skill scores of girls and boys was found insignificant. However, locomotor skill total test score of boys was determined to be higher than that of girls.

Kelly et al. (2019) in their study with 414 Irish children between 6 and 12 years of age, did not find a significant difference between girls and boys according to TGMD-III locomotor test results depending on gender variable. Burns et al. (2017a) analysed the relationship between gross motor skills and cardio-metabolic risk in children in 2017. In their study with 224 children (mean age 9 years) in the United States, they used the TGMD-III test to assess gross motor skills of the children. As a result of the data obtained in the study, they could not find a significant difference between locomotor skill levels of male and female students. Similarly, in 2017, Burns et al. (2017b) examined multivariate relationships between health-related fitness, physical activity, and TGMD-III test items in children of low-income families. 1460 school-age children (4-8 years) of low-income families, 730 female and 730 male, participated in the study. In the study, no significant difference was found between locomotor skills in score and it was stated that locomotor skills of girls and boys were in the same condition. Again, Webster and Ulrich evaluated the psychometric properties of the TGMD-III test in 2017. 424 men were included in the study involving a total of 807 children (3-6 years), 383 girls and 424 boys. At the end of the study, similar scores were found in locomotor skills between boys and girls.

In 2018, Aye et al. (2018). examined the gross motor skills development in 5 years old kindergarten children in Japan. In the study, a total of 60 healthy children, 34 boys and 26 girls, were examined using TGMD-II. They found that the locomotor skill scores of the girls were significantly higher than the boys. The locomotor raw score

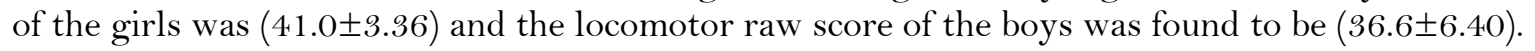

In the TGMD-III Object Control Test Results, Aye et al. (2018). studied gross motor skills development of 60 (34 boys and 26 girls) healthy 5 years old kindergarten children in Japan in 2018. Subjects were measured using TGMD-II. As a result of the study, they found that the boys' basic object control skill scores were better than the girls. The object control skill raw score of the girls was (34.5 \pm 6.62$)$ and the object control skill raw score of the boys was found to be (37.8 \pm 6.24$)$. In 2017, Allen et al. (2017) performed the validity and reliability of gross motor development test-3 (TGMD-III) in children with autism spectrum disorder using visual support. A total of 14 children between the ages of 4-10 years participated in the study. At the end of the study, they could not find any difference between the object control skills of autistic boys and girls. It was seen that the boys' object control skill scores were higher than the girls.

In their study, Burns et al. (2017a) analysed the relationship between gross motor skills and cardio-metabolic risk in children in 2017 and used TGMD-III test to evaluate the gross motor skills of the children. As a result of the data obtained in the study, it was found that the object control skill levels of the male students were significantly better than the girls $(\mathrm{p}<0.01)$. Burns et al. $(2017 \mathrm{~b})$ also examined multivariate relationships between health-related fitness, physical activity, and TGMD-III test items in children of low-income families in the USA in 2017. 1460 school-age children (4-8 years), 730 female and 730 male, participated in the study. In their study, they determined that object control skills of the boys were statistically significantly better than the girls $(p<0.01)$. Likewise, Zeybek's study comparing the basic motoric characteristics of 9-year-old children at primary school in Beypazarı district of Ankara could not find a significant difference between the mean object control skills of the male and female students. However, it was seen that the boys' object control skill scores were better than the girls.

In terms of the TGMD-III total test scores, there are studies in the literature that are in parallel with our study. For example, Burns et al. (2017a). analysed the relationship between gross motor skills and cardio-metabolic risk in children in 2017. In their study with 224 children (mean age 9 years) in the United States, they used the TGMD-III test to assess gross motor skills of the children. As a result of the data obtained from the study, a statistically significant difference was found between TGMD-III test scores of male and female students $(p<0.05)$. It was found that the boys' TGMD-III test scores were higher than the girls. Webster and Ulrich also evaluated the psychometric properties of the TGMD-III test in 2017. A total of 807 children (3-6 years), 424 boys and 383 girls, participated in the study. As a result of the study, when TGMD-III test scores were examined, it was seen that TGMD-III total test scores of boys were higher than those of the girls. In 2011, Ylldirım investigated the psychomotor development levels of girls and boys in the age group of seven and eight in terms of gender variable according to the TGMD-II test and the difference between TGMD-II test total scores of the boys and girls was found to be statistically insignificant. However, the TGMD-II test total score of boys was found to be higher than that of the girls.

It is thought that the difference in the measurement results in terms of gender in the studies was due to different age groups. There are also many other factors like physical activity levels and socio-economic levels of the 
participants. However, in the light of the information given in psychomotor development, it is stated that there are not very significant differences between the motor skills development of children until adolescence on gender basis. It has been stated that some motor features come into prominence from time to time during the developmental periods. However, the general opinion is that the motor development of girls and boys is very close to each other until adolescence.

In comparison of TGMD-III test results and sports branches, there is a statistically significant difference in total locomotor tests, object control tests total and TGMD-III overall total $(\mathrm{p}<0.01)$.

Aydin (2009) investigated the motor development levels of the 10-age group students, who participated indoor sports events in the city of Kütahya, according to TGMD-II test and showed that the difference between TGMDII test locomotor skill levels was significant depending on sports branch $(\mathrm{P}<0.05)$.

Bastik (2011) investigated the basic motor characteristics of 10-year-old athletes participating in competitions in individual, dual and team sports according to TGMD-II test. In that study, taekwondo and swimming were included under the name of individual sports while table tennis and tennis were included under the name of dual sports, and football and handball were included under the name of team sports. TGMD-II locomotor test results showed that the difference between the children's TGMD-II locomotor subtest scores was significant in terms of sports branch $(\mathrm{P}<0.01)$.

Aydin (2009) investigated the motor development levels of the 10-age group students, who participated indoor sports events in the city of Kütahya, according to TGMD-II test and showed that the difference between TGMD II test object control skill levels was significant depending on sports branch $(\mathrm{P}<0.05)$.

Bastik (2011) investigated the basic motor characteristics of 10-year-old athletes participating in competitions in individual, dual and team sports according to TGMD-II test. In that study, taekwondo and swimming were included under the name of individual sports while table tennis and tennis were included under the name of dual sports, and football and handball were included under the name of team sports. TGMD-II locomotor test results showed that the difference between the children's TGMD-II locomotor subtest scores was significant in terms of sports branch $(\mathrm{P}<0.01)$.

Akin et al. (2016) in their study comparing the basic motor skills levels of the 10-11 age group athletes participating in the inter-school competitions in 2016 and non-sports children, conducted "bidirectional coordination, balance, running speed and agility and power" tests. In that study, they compared basketball, badminton branches and a non-sports group. As a result, they revealed that the gross motor skills of basketball players and badminton players were statistically better than those who did not do sports. While they didn't mention about a statistical significance between basketball players and badminton players, they stated that the measurement data of the basketball players in the gross motor skill tests were better than badminton players.

Aydin (2009) investigated the motor development levels of the 10-age group students, who participated indoor sports events in the city of Kütahya, according to TGMD-II test and showed that the difference between TGMD II test total skill levels was significant depending on the sports branch.

The results of our study and similar and related studies in the literature were examined. Branch evaluations were made in the literature and in our study. In the studies, it was observed that the measured characteristics of athletes interested in team sports were generally higher. It is thought that this resulted from the need for highly developed motor skills in the mentioned sports branches (football, basketball) due to their popularity and competitive environment. Besides, differences in participants, individual characteristics of athletes, environmental factors and variables such as training and sport age may have caused these results. Similar results have been observed in the related studies in the literature (Aydin, 2009; Akin et al., 2016). The results of these studies support our study. However, due to the insufficiency of studies in the literature, there are limited resources to evaluate and no samples were found for our variables.

\section{Conclusion}

According to the data obtained, it was found that boys' gross motor skills were better than girls' gross motor skills. The general belief in the literature for the reason for this difference between boys and girls is socio-cultural reasons and the developmental parameters in favour of boys with age.

Another parameter evaluated in the study was the branches. Statistically significant differences were observed between branches and gross motor skills. Based on the data obtained, it was determined that football players had significantly better gross motor skills, which was followed by basketball and taekwondo respectively. Gross motor skills of the athletes in gymnastics and volleyball branches were seen to be lower than the other branches.

As a result, it was seen that gross motor skills of football players were significantly better in comparison with other branches. Locomotor, object control and total TGMD-III test scores of male athletes were found to be better than girls. In the football branch, it is thought that 48 athletes were all male and this may have led to high football scores. In the volleyball and gymnastics branches, low locomotor, object control and total TGMD-III test scores are thought to be due to high number of girls and low number of boys.

In addition, it is thought that the difference between the branches resulted from the motoric and physiological characteristics required by the structures of the branches. Besides, sports age and training styles of the athletes are thought to affect the measurement results.

\section{References}

Akin, S., A. Kalkavan and M. Gülaç, 2016. Comparison of 10-11 years old athletes participating in interscholastic competitions and nonathletes children's fundamental motor skills. Sportive Sight: Journal Of Sport And Education, 3(1): $21-32$.

Allen, K., B. Bredero, T. Van Damme, D. Ulrich and J. Simons, 2017. Test of gross motor development-3 (tgmd-3) with the use of visual supports for children with autism spectrum disorder: Validity and reliability. Journal of Autism and Developmental Disorders, 47(3): 813-833.Available at: https://doi.org/10.1007/s10803-016-3005-0.

Aydin, S., 2009. Invistigate the motor development levels of the first stage primary school 10 age-group students who participate indoor sports in Kütahya City. Master Thesis, Dumlupınar University.

Aye, T., T. Kuramoto-Ahuja, T. Sato, K. Sadakiyo, M. Watanabe and H. Maruyama, 2018. Gross motor skill development of kindergarten children in Japan. Journal of Physical Therapy Science, 30(5): 711-715.Available at: https://doi.org/10.1589/jpts.30.711. 
Bastik, C., 2011. The investigation of basic motor characteristics according to tgmd-II test to ten age group athletes participating competitions in individual, Dual and team sports. Master Thesis, Dumlupinar University.

Bilgiç, M., M. Biçer and M. Özdal, 2016. Investigation of relation 2D: 4D finger ratio and sportive performance of 11-13 aged children participated in different sports. Gaziantep University Journal of Sport Sciences, 1(1): 48-56

Burns, R., T. Brusseau, Y. Fu and J. Hannon, 2017a. Gross motor skills and cardiometabolic risk in children: A mediation analysis. Medicine and Science in Sports and Exercise, 49(4): 746-751.

Burns, R., T. Brusseau and J. Hannon, 2017b. Multivariate associations among health-related fitness, physical activity and TGMD-III test items in disadvantaged children from low-income families. Perceptual And Motor Skills, 124(1): 86-104.

Dündar, U., 1995. Training theory, 2. print, Ankara: pp: 16-95.

George, D. and P. Mallery, 2010. Spss for windows step by step: A simple guide and reference. 17.0 update. 10th Edn., Boston: Pearson.

Kelly, L., S. O'Connor, A.J. Harrison and N.J. Ní Chéilleachair, 2019. Does fundamental movement skill proficiency vary by sex, class group or weight status? Evidence from an irish primary school setting. Journal of Sports Sciences, 37(9): 1055-1063.Available at: https://doi.org/10.1080/02640414.2018.1543833.

Koç, S., 2005. Skill development in physical education and sports. Istanbul: Morpa Kültür Publications.

Kürkçü, R. and I. Gökhan, 2011. The effects of handball training on the some respiration and circulatory parameters of school boys aged 1013 years. Journal of Human Sciences, 8(1): 135-143.

Spessato, B.C., C. Gabbard, N. Valentini and M. Rudisill, 2013. Gender differences in Brazilian children's fundamental movement skill performance. Early Child Development and Care, 183(7): 916-923.Available at: https://doi.org/10.1080/03004430.2012.689761.

Timmons, B., P.-J. Naylor and K.A. Pfeiffer, 2007. Physical activity for preschool children-how much and how? C J Public Health, 98(S2E): $122-134$.

Webster, E.K. and D.A. Ulrich, 2017. Evaluation of the psychometric properties of the test of gross motor development. Journal of Motor Learning and Development, 5(1): 45-58.Available at: https://doi.org/10.1123/jmld.2016-0003. 